\title{
Progressions
}

Author reflections on developments since the publication of "The Establishment of Polarity by Hippocampal Neurons in Culture,” by Carlos Dotti, Chris Sullivan, and Gary Banker. (1988) J Neurosci 8:1454-1468.

\section{The Development of Neuronal Polarity: A Retrospective View}

\author{
(1)Gary Banker \\ Jungers Center for Neurosciences Research, Oregon Health and Science University, Portland, Oregon 97239
}

In 1988, Carlos Dotti, Chris Sullivan, and I published a paper on the establishment of polarity by hippocampal neurons in culture, which continues to be frequently cited 30 years later (Dotti et al., 1988). By following individual neurons from the time of plating until they had formed well developed axonal and dendritic arbors, we identified the five stages of development that lead to the mature expression of neuronal polarity. We were surprised to find that, before axon formation, the cells pass through a multipolar phase, in which several, apparently identical short neurites undergo periods of extension and retraction. Then one of these neurites begins a period of prolonged growth, becoming the definitive axon; the remaining neurites subsequently become dendrites. This observation suggested that any of the initial neurites were capable of becoming axons, a hypothesis confirmed by later work. In this Progressions article, I will try to recall the circumstances that led to this work, recapture some of the challenges we faced in conducting these experiments, and consider why some of today's neuroscientists still find this paper relevant.

\section{Introduction}

"Neurons are highly polarized cells.... " "Neurons are among the most highly polarized cell types in the body." "The most distinct feature of neurons is their polarized morphology." As these introductory sentences from recent review articles make clear, the concept of neuronal polarity is now widely accepted and has taken on a central role in the way we think about neurons. This was not the case when Carlos Dotti, Chris Sullivan, and I began the work described in Dotti et al. (1988). Of course, the anatomical differences between axons and dendrites had been appreciated since the time of Deiters and Cajal's Law of Dynamic Polarization posited that dendrites receive incoming information while the axon conveys information to downstream target cells (Shepherd, 1991). But in the 1960s, the advent of electron microscopy and intracellular electrophysiological recording led to the discovery of dendro-dendritic, axo-axonal, and reciprocal synapses. Thus, it became clear that the directionality of neuronal signaling was far more complicated than envisioned in Cajal's time. Neurons were understood to be composed of a number of structurally and functionally distinct compartments-presynaptic terminals and postsynaptic specializations, nodes and internodesbut the idea of neuronal polarity had fallen out of favor. Our paper (Dotti et al., 1988) was one of several from that period that helped to recast the idea of neuronal polarity in the context of cell and

Received Dec. 11, 2017; revised Jan. 4, 2018; accepted Jan. 5, 2018.

This article is dedicated to The Journal of Neuroscience - to its first editor, to those who followed in his footsteps, and to all those in the neuroscience community who have contributed to its remarkable success. My thanks to all the members of the Bankerlab who have made my career in science so much fun.

The authors declare no competing financial interests.

Correspondence should be addressed to Dr. Gary Banker, The Jungers Center, Mail Stop L-623, Oregon Health and Science University, 3181 SW Sam Jackson Park Road, Portland, OR 97239. E-mail: bankerg@ohsu.edu.

DOI:10.1523/JNEUROSCI.1372-16.2018

Copyright $\odot 2018$ the authors $\quad 0270-6474 / 18 / 381867-07 \$ 15.00 / 0$ developmental biology rather than from a purely physiological perspective.

Although our paper describes a series of experiments undertaken in the mid-1980s in my laboratory at Albany Medical College, the work really began in 1973, when I began my postdoctoral research in Max Cowan's laboratory at Washington University. As a graduate student with Carl Cotman, I was encouraged to read widely, which led me to an interest in how neurons develop their characteristic dendritic shape and form specific synaptic connections (Cotman and Banker, 1974). Max had discussed the importance of such questions in several elegant review articles he wrote on neural development. (For a description of Cowan's life and contributions to neuroscience, see Cowan, 2004). In thinking of strategies to address these questions, both Max and I were inspired by recent cell culture studies of peripheral and spinal cord neurons, work that, for the first time, allowed direct observation of neuronal growth and branching (Bray, 1970, 1973) and of neuromuscular synapse formation (Fischbach, 1972). We became convinced that directly observing neuronal development, rather than making inferences about development from observations of fixed tissue, would yield new insights into the mechanisms involved.

Max, who had a longstanding interest in the anatomy of the hippocampus, suggested that this might be an ideal tissue for study in culture. Its cellular composition is relatively homogeneous because pyramidal cells account for the great majority of its neurons, and these cells have a distinctive dendritic architecture and make specific, well-known synaptic connections. Our objectives in undertaking this work placed strong constraints on the cell culture methods that could be used. To follow the growth of individual cells, the cultures had to be established at low density, ideally using buffers that allowed them to be observed in an air 
atmosphere. Obtaining quality images by phase contrast or differential interference contrast microscopy meant that the cells must be grown on glass coverslips rather than in plastic dishes. Having had no experience in cell culture of any kind, I had no idea that these constraints might make growing hippocampal neurons difficult. In the event, establishing conditions that allowed hippocampal neurons to develop normally in culture and form synaptic networks was not accomplished until long after I left Max's laboratory and began my independent career.

\section{Learning to culture hippocampal neurons}

Fortunately for me, Dick and Mary Bunge were among the first neuroscientists Max recruited to Washington University after assuming the chair of Anatomy and Neurobiology. They were among the world's foremost experts on neuronal culture, particularly as a model for studying myelination. (For an appreciation of their contributions to neuroscience, see Bunge, 2004.) From them and their colleagues, I received my introduction to sterile technique, learned that I needed something called a laminar flow hood, and was taught the ins and outs of observing cultured neurons by light and electron microscopy. Working initially with David Haynor, another postdoc in Max's laboratory who subsequently went on to medical school and a career in neuroradiology, we undertook many months of experiments, varying medium composition, buffers, and supplements, and testing serum from countless sources (our own included), hoping to find conditions that allowed hippocampal neurons to survive long enough to put out neurites. Amid countless failures, there were occasional hints of success, and we were able to watch growing neurites and observe growth cone motility. I found this so addicting that I continued looking for some magic strategy to make better cultures long after good sense might have suggested moving on to a different project.

\section{Finding the right substrate}

Ross Harrison's initial studies of neurons in culture showed that nerve outgrowth requires a solid substrate (Harrison, 1914). When we began this work, collagen purified from rat tails was the only option available. Although this worked well for explant cultures, we soon found that it was a poor choice for dissociated hippocampal neurons. In the spring of 1974, I became aware of unpublished work by Paul Letourneau, then a graduate student in Norman Wessells' laboratory at Stanford, who found that polylysine was an excellent substrate for DRG cultures. Letourneau kindly shared his results and sent his protocol for treating substrates with polylysine, work that he published the following year (Letourneau, 1975). Polylysine proved an excellent substrate. Both adhesion and neurite outgrowth were markedly better than on collagen, and results were much more consistent.

\section{Appreciating the role of trophic factors}

Culturing hippocampal neurons on polylysine enabled the cells to initiate neurite outgrowth, but they only survived for a few days. A series of observations over the next year led to an appreciation of the importance of trophic interactions for neuronal survival and to a strategy for providing trophic support in culture. One clue came from an experiment suggested by Dick Bunge. When describing my frustration that hippocampal neurons grew well initially but died after a few days, he mentioned that, in his experience, this sometimes happened because cells depleted the medium of essential nutrients. To test this idea, he suggested changing the medium on a daily basis. I quickly discovered that, rather than enhancing cell growth, frequently changing the medium hastened the onset of cell death. At about the same time, I began to examine how cell plating density influenced growth in culture. The goal was to promote the attachment of individual neurons to the substrate while minimizing the formation of cell aggregates, which form when dissociated neurons adhere to one another while still in suspension. By systematically varying plating density, I found that increasing cell density enhanced neurite growth and found a "sweet spot," a plating density high enough to allow neurite outgrowth but low enough to minimize aggregation. Putting this observation together with the effects of medium change suggested that the neurons themselves were "conditioning" the medium by releasing factors important for their own survival.

The method I arrived at for providing trophic support in culture, which was also stimulated by work in the Bunge laboratory, offers a nice example of serendipity at work. Dick Bunge and colleagues (Bunge et al., 1974) developed a clever approach to study synapse formation by coculturing dissociated sympathetic neurons with spinal cord explants. The explants gave off a halo of nerve fibers that served as a rich source of presynaptic fibers that innervated the dissociated cells. I decided to try the same idea, using explants of hippocampus as a source of innervating fibers. What I had not expected, but was immensely pleased to see, was that the dissociated hippocampal neurons grew much better and survived far longer than under any conditions I had ever seen before. Rather than dying after a few days, cells survived for as long as 2 weeks. This was true even for neurons that were far from the explant outgrowth zone. Max and I interpreted this result as evidence that neurons within the explants were releasing factors that promoted survival of the dissociated neurons. Coculture with explants became our standard method for preparing cultures and allowed us to make some initial observations on the development of hippocampal neurons (Banker and Cowan, 1977, 1979).

The final chapter in this part of the story happened shortly after I moved to Albany Medical College in 1976. There I met Harry Kimelberg from the Department of Neurosurgery, who was interested in the role of astrocytes in normal brain function and in the response to traumatic injury. He raised the possibility that the survival factor arising from explants was released by glia, not neurons. There was growing evidence at that time that a neuron's survival depended on molecular signals exchanged with its synaptic partners, so it seemed obvious to me that neurons in the explant were the source of trophic support. But Kimelberg was insistent and prepared astrocyte cultures for us to test, so it was difficult to avoid trying the experiment he suggested. And, of course, he was right: astrocyte cultures performed beautifully to support neurons and were much easier and more reproducible to work with than explant cultures (Banker, 1980). We have continued to use astrocyte coculture ever since; to my knowledge, the factors responsible for this effect have never been identified.

\section{Getting the right medium}

The last major piece of the puzzle was brought to my laboratory by Anne Messer, literally. Then a member of the Wadsworth Center of the New York State Department of Health, Messer had heard a presentation by Gordon Sato describing his work with Jane Bottenstein to develop a serum-free medium that supported the growth of neuroblastoma cells in culture (Bottenstein and Sato, 1979). At that time, the idea of finding a way to grow cells that did not depend on serum was like finding the Holy Grail. Messer found that Bottenstein and Sato's N2 medium worked well for her cerebellar cultures and brought some for us to try 
with hippocampal cells. It was miraculous. On the first try, we were able to keep neurons alive and healthy for 4 weeks, far longer than ever before. A note from an early experiment states: "cultures are absolutely luscious- better than any we've ever had." And growth in N2 was consistent. No more need to test lot after lot after lot of human placental serum. At about this time, we also gave up on trying to grow neurons in buffers that could be equilibrated in air and switched to using bicarbonate, like everyone else.

Thus, after 6 years, the fundamentals for successfully growing hippocampal cultures had been established: plate the cells at low density onto polylysine-treated glass coverslips, coculture them with astroglia growing on a separate substrate, and use N2 medium. With those key factors combined, we consistently obtained cultures that survived for a month or more, grew beautiful axons and dendrites, and underwent extensive synaptogenesis. Now, almost 40 years later, our methods for culturing hippocampal neurons have changed only minimally (Kaech and Banker, 2006).

\section{Are the neurites that grow in hippocampal cultures axons or dendrites?}

Once we were able to culture neurons for more than a few days, one of the questions that arose in my conversations with Max was whether the neurites that formed in hippocampal cultures were axons or dendrites. Surprisingly, previous studies of dissociated neuronal cultures failed to consider this question, perhaps because people were so happy to observe some kind of neurite growth in culture that they did not want to inquire too deeply about the nature of these processes. But for someone like Max, with a strong background in neuroanatomy, it was a natural question to ask. I recall him saying something like "When you say neurites, Gary, do you mean axons or dendrites?" and the tone he used in enunciating "neurites" made it clear he felt use of such an imprecise term exemplified the sloppy science he so deplored. Once we began to look at the cultures with this question in mind, it seemed that, in older cultures, the processes we could trace growing out from cells most closely resembled dendrites, gradual in origin, tapering with distance from the soma, and branching in acute angles. Indeed, we were able to find occasional cells that seemed to have one apical dendrite and several basilar dendrites, like pyramidal neurons do in vivo (Banker and Cowan, 1979). The thin processes that formed a background network seemed more like axons, but it was not possible to tell whether they arose from cell bodies, like axons in vivo, or were simply continuations of distal dendrites, a kind of process never observed in real neurons.

It took nearly 10 years, and the work of several dedicated students and postdocs, to definitively answer this question. By growing cells at very low density, it was possible to visualize individual cells in their entirety. After a week in culture, such cells gave rise to a single, long neurite with the morphological features of an axon and several, shorter dendrite-like neurites. Then by observing the same cells at the electron microscopic level, Bill Bartlett, my first graduate student, showed that the processes identified as axons and dendrites based on their length and branching pattern exhibit the ultrastructural features that characterize axons and dendrites in intact tissue (Bartlett and Banker, 1984a). In high-density cultures, the dendrites were postsynaptic and the axons presynaptic (Bartlett and Banker, 1984b). In retrospect, these are probably the most difficult experiments ever attempted in my laboratory because they required capturing an entire neuron in a few sections only $80 \mathrm{~nm}$ thick. A bit later, Alfredo Cáceres, a postdoc in the laboratory, used immunostain- ing to show that the recently discovered marker MAP2 selectively labeled dendrites in culture (Cáceres et al., 1986), and I found that nicotinic receptors, identified by bungarotoxin binding, were also restricted to dendrites. Moreover, the compartmentation of receptors and of MAP2 occurred in isolated cells, independent of cell-cell interactions. This set of experiments demonstrated that hippocampal neurons in culture establish multiple dendrites and a single axon, and that these two sets of processes are molecularly distinct and play distinct roles in neural signaling. These results changed how we thought about neurons, from cells that were a composite of different cellular regions (presynaptic and postsynaptic specializations, nodes and internodes), to cells whose most basic property was their polarization into axonal and dendritic domains.

\section{The development of neuronal polarity}

This was the situation when Carlos Dotti joined my laboratory in 1985. In our discussions together and with other members of the laboratory, Carlos and I focused on polarity and on how neurons compared with other types of polarized cells, like epithelial cells. This point of view led us to a set of questions that seemed to be of fundamental importance but that had not received much attention from neuroscientists. From a developmental perspective, what are the events that lead to the emergence of polarity? From a cell biological perspective, what are the steps in protein trafficking that underlie the biochemical differences between axons and dendrites? These questions would come to occupy both of us for many years to come.

Carlos and I decided to focus first on the developmental question. After a day or two in culture, hippocampal neurons have one long process and several shorter ones, but the relationship of these neurites to the axons and dendrites that could be recognized at later stages was unclear. Was the long neurite the forerunner of the apical dendrite and the short neurites basilar dendrites, as we and others initially proposed, or was the long neurite an axon and the remaining neurites dendrites? What developmental processes led to axon and dendrite formation? To answer such questions, we needed to follow the development of individual neurons from the time of plating until polarity had fully emerged. We knew these experiments would require long hours of imaging, testing our stamina and dedication, so we were particularly pleased when Chris Sullivan, a medical student interested in fundamental research, enthusiastically agreed to participate in this work.

In today's world, where individual cells can be visualized by expressing a fluorescent marker protein, automated microscopes can sequentially capture images at multiple stage positions and ensure that each image is in crisp focus, and there are sophisticated chambers for maintaining the proper cellular environment during microscopic imaging, following a neuron's development is a comparatively simple task. It was not so easy then. The observations described in this paper were obtained in two ways. In one set of experiments, cells of interest were identified early on in culture and photographed with a $35 \mathrm{~mm}$ camera; then the dishes were returned to the incubator and periodically put back on the microscope stage so the cells could be relocated and rephotographed. This process was continued until the cells showed clear axons and dendrites, which took approximately a week in culture. Some of these cultures were subsequently fixed and stained for MAP2, with the hope that we might relocate the same neurons that had been followed. Other experiments attempted to detail the changes that occur in the first $24-48 \mathrm{~h}$ in culture by making continuous time-lapse recordings of individual cells, using a videotape recorder designed to photograph robberies at conve- 


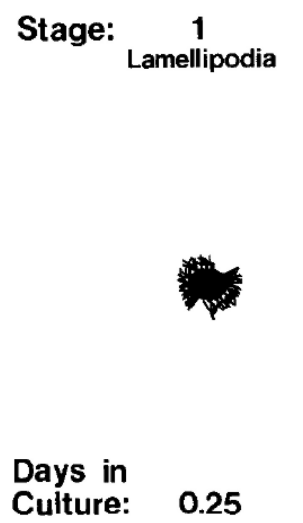

Days in
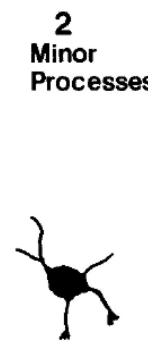

3

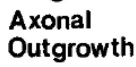

0.5

1.5
4

Dendritic

Outgrowth

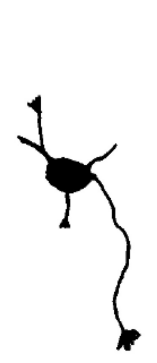

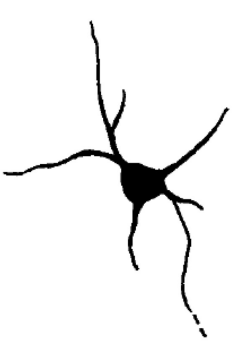

4

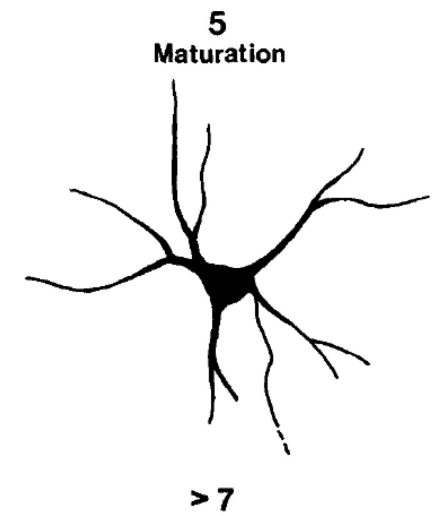

Figure 1. Stages of development of hippocampal neurons in culture. The approximate times when cells enter each of the stages are indicated. Reproduced with permission from Dotti et al. (1988).

nience stores and a glorified hair dryer to maintain temperature. Many experiments were lost because cells died or went out of focus or because processes from neighboring cells became entangled with those we were hoping to follow, but eventually we obtained enough data to assemble an accurate picture of the events that led to the establishment of axonal and dendritic arbors.

The results were clear. The long neurite seen in young cells was the axon. It grew at a rate much faster than the other neurites, branched in a pattern typical of axons, and was MAP2-negative. The short neurites began to grow somewhat later and at a much slower rate, becoming the cell's dendrites. To our knowledge, this was the first time that these developmental events had been followed in living neurons. The findings were consistent enough that we were able to distinguish five stages that characterize the development of hippocampal neurons in culture, which we illustrated in the final figure in our paper (reproduced here in Fig. 1). Other laboratories subsequently found that cultured cortical neurons follow a similar pattern of development. In retrospect, it is clear that much of the impact of this paper arose from codifying these stages and capturing their key features in a simple drawing, which has frequently been reproduced in other articles. Interestingly, this figure was an afterthought, added in the process of revising the manuscript in response to other concerns raised by the reviewers.

The video recordings made during the first day or two in culture revealed something quite unexpected (Fig. 2). Stage 2 of development, before outgrowth of the axon, was characterized by an unusual pattern of growth. First, one neurite grew rapidly for a brief period; then it stopped growing and a different neurite began to
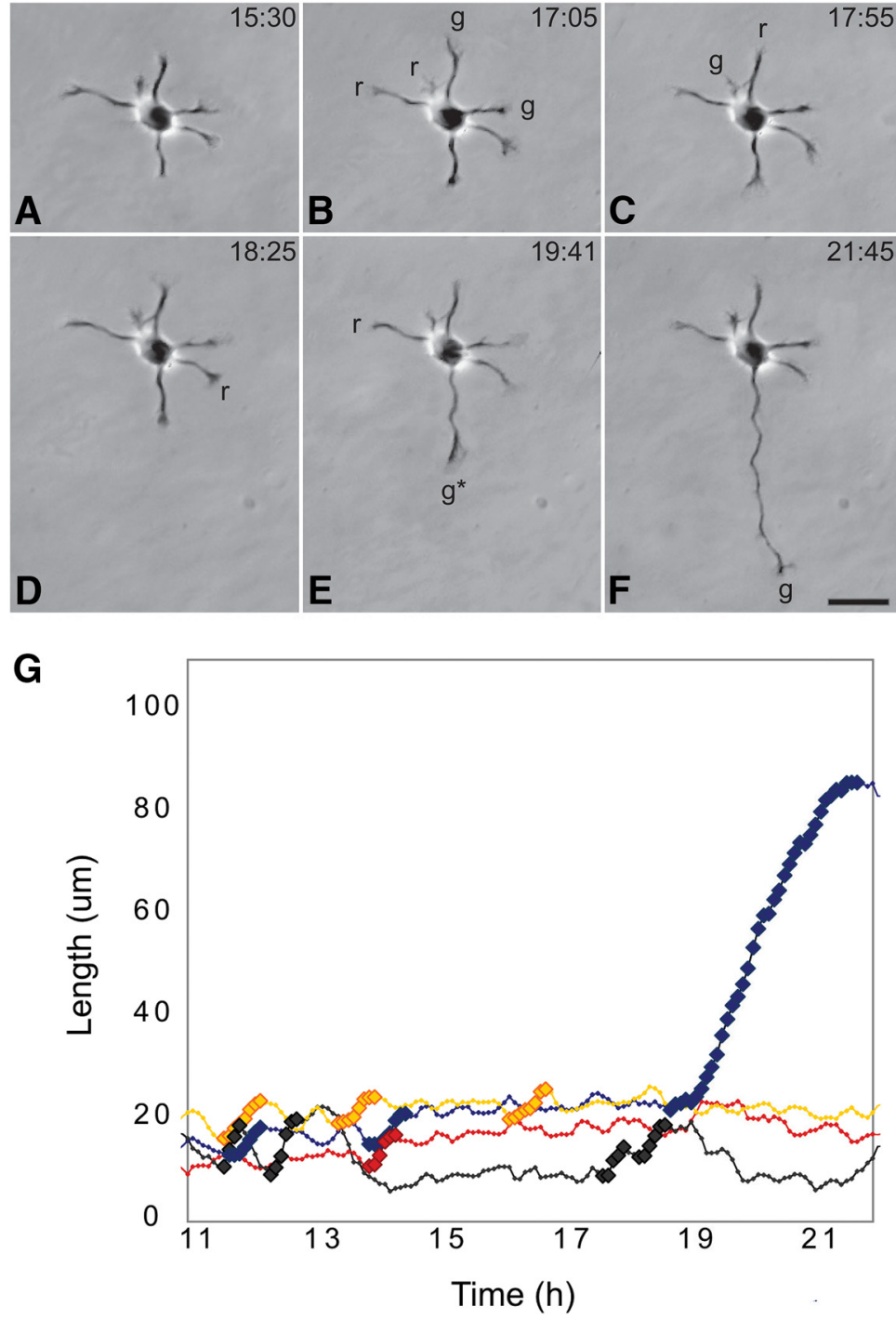

Figure 2. Axonal specification is marked by a profound change in the pattern of neurite growth and retraction. $\boldsymbol{A}-\boldsymbol{F}$, Single frames from a time lapse recording illustrating phases of growth and retraction during Stage 2 and Stage 3 of development. Before the axon formed, different minor neurites exhibited periods of growth $(\mathrm{g})$ followed by periods of retraction $(\mathrm{r})$. Eventually, one process began to grow $\left(^{*}\right)$ and did not retract, but instead developed into the axon. The times shown refer to hours and minutes after plating. $\mathbf{G}$, Graph representing changes in the length of four different neurites from this same cell before and after axon specification. Bold symbols indicate growth spurts. The $x$ axis shows time after plating. This figure, showing data collected since our original work, offers a clearer view of these events, thanks to improved imaging equipment and the availability of Adobe Photoshop (Teresa Esch, unpublished observations). 
grow. This pattern continued until eventually one neurite entered a growth phase that persisted until it reached a length of 75-100 $\mu \mathrm{m}$. This process became the axon, and the remaining neurites became dendrites. Before the axon was specified, we could not identify any feature that distinguished it from the other neurites. These observations suggested that any of the initial processes might be capable of becoming axons and that in culture, in the absence of spatially organized extracellular signals, which neurite becomes the axon is a matter of chance. If this idea were correct, then cutting off the initial axon might allow a different neurite to become the axon. This is exactly the result Carlos observed (Dotti and Banker, 1987; see also Goslin and Banker, 1989). Subsequent work showed that a variety of experimental manipulations can induce any Stage 2 neurite to become the axon (Esch et al., 1999; Lamoureux et al., 2002; Yamamoto et al., 2012; Takano et al., 2017).

We assumed that Stage 2 of development was a kind of cell culture "artifact." In vivo, there must be cues in the extracellular environment to ensure that the axons of hippocampal and cortical pyramidal neurons do not arise in random orientations but are directed toward the white matter. We thought that, in culture, where such cues are lacking, considerable time might be required for small, randomly occurring differences among neurites to be amplified enough for one neurite to become the axon. This assumption turned out to be incorrect. It has since been shown that cortical neurons in situ undergo a multipolar stage, also lasting about a day, that is characterized by growth and retraction of multiple neurites (Tabata and Nakajima, 2003; Noctor et al., 2004). Thus, this aspect of our observations of cultured neurons turned out to have a relevance for development in vivo that was not appreciated at the time.

There were two other specific findings that we emphasized in this paper because they contradicted then-prevailing views on neural development. The first was the observation that the development of neuronal polarity was cell autonomous. In the 1980s, there was a strong emphasis on the role of cell interactions in shaping neuronal development, and some had even suggested that dendritic growth was initiated only after contact with innervating axons. The idea that polarity could be established without such interactions was quite novel. Second, we wanted to call attention to the importance of interstitial branching in the formation of axonal arbors. At that time, Dennis Bray's work showing that cultured sympathetic neurons branched by growth cone bifurcation was so compelling that no other possibilities were given serious consideration. We have since learned much about the mechanisms of interstitial branching and now appreciate that the selective maintenance of particular subsets of interstitial branches plays an important role in determining the selectivity of neuronal connections (Luo and O'Leary, 2005; Armijo-Weingart and Gallo, 2017).

Following the completion of this work, Chris Sullivan returned to medical school and Carlos Dotti joined Kai Simons's laboratory at EMBL to explore parallels between polarity in hippocampal neurons and epithelia, then continued these studies in his own laboratory. Carlos's work uncovered numerous similarities between the protein trafficking mechanisms in the two cell types, work that laid the foundation for our current understanding of the maintenance of neuronal polarity (Dotti and Simons, 1990; Cid-Arregui et al., 1995). Work in my laboratory continued to exploit hippocampal cultures to address questions of neuronal cell biology and neuronal development. For example, we were able to show that axons and dendrites differ in microtubule polarity orientation (Baas et al., 1988), which has important impli- cations for motor-driven transport, and in collaborative work with Oswald Steward, characterized the localization and transport of RNA in dendrites (Kleiman et al., 1990; Steward and Banker, 1992). We also identified actin waves, a novel form of actin transport that is now thought to play a role in axon specification, perhaps by modulating microtubule-based transport (Ruthel and Banker, 1999; Flynn et al., 2009; Winans et al., 2016). Finally, we described some of the extracellular signals that regulate axonal and dendritic growth (Esch et al., 1999, 2000; Withers et al., 2000) and characterized synaptic development in hippocampal cultures, including the formation of presynaptic specializations and the clustering of postsynaptic receptors and subsynaptic scaffolding proteins (Fletcher et al., 1991, 1994; Craig et al., 1994, 1996). As a result of such work, hippocampal cultures became a commonly used model system for developmental and cellular neuroscientists.

\section{Hippocampal cultures and neuronal polarity, three decades on}

In the 30 years since this paper was written, we have seen almost unimaginable progress in our understanding of neural development and in the technologies available for its study. In 1988, cell culture was the only way one could observe living neurons. With the advent of two-photon microscopy and in utero electroporation, the rationale that motivated our work with hippocampal cultures no longer applies. One might think that the cultures characterized in this ancient paper would long since have become obsolete, but that is not the case. Hippocampal and cortical cultures are comparatively straightforward and inexpensive to prepare and still offer unparalleled access for imaging and manipulation of living cells. Moreover, as new methodologies arose, the cultures proved to be quite adaptable. Early on, low-density cultures proved particularly suitable for immunofluorescence microscopy; when methods for engineering fluorescent proteins became available, the cultures were ideal for live-cell imaging. When it became possible to express foreign genes using viruses or transfection, to block gene expression using siRNAs, and to manipulate the genome with CRISPR, applying these new strategies to hippocampal cultures was relatively simple. With the advent of methods for knocking out or mutating genes in transgenic mice, cultures prepared from such animals offered a valuable way to analyze the functions of the missing gene.

Thus, hippocampal cultures continue to be widely used for cell biological studies of the neuronal cytoskeleton, for analysis of motor-driven transport, and for studies on protein trafficking (Feng and Arnold, 2016; Nirschl et al., 2017). They offer a useful model for elucidating the signaling pathways underlying axonal and dendritic growth, for identifying novel presynaptic and postsynaptic organizing factors and, in combination with knock-out experiments, for elucidating their mechanisms of action (Siddiqui and Craig, 2011; Lewis et al., 2013). Hippocampal cultures have also been useful for understanding the factors that make neurons susceptible to disease and in assays seeking to enhance neuronal survival or foster axonal regeneration (Ashrafi et al., 2014; Fang et al., 2016; Al-Ali et al., 2017).

The specific questions raised by our observations on the development of neuronal polarity also remain active topics for research. From the cell biological perspective, how is it that proteins synthesized in a common compartment are differentially delivered to axonal and somatodendritic domains? This question has driven much of the research in my laboratory over the past decade. In the case of membrane proteins, current evidence suggests that axonal and dendritic proteins are sorted into different vesicles as they leave the Golgi complex, then undergo selective 
microtubule-based transport to reach their final destinations in the cell (Bentley and Banker, 2016). Vesicles carrying dendritic proteins are prevented from entering the axon; vesicles carrying axonal proteins, though not excluded from the dendrites, are preferentially transported toward the axon. Selective exocytosis may also play a role in axonal protein trafficking (Soo Hoo et al., 2016). Our current understanding of the mechanisms involved is summarized in a recent review (Bentley and Banker, 2016).

From a developmental perspective, how is it that an unpolarized neuron with several, apparently identical processes, comes to form a single axon and multiple dendrites that are morphologically and molecularly distinct? Several recent reviews summarize the remarkable progress that has been made in addressing this question (Namba et al., 2015; Schelski and Bradke, 2017; Yogev and Shen, 2017). Although in culture the neurite that becomes the axon is largely a matter of chance, in vivo the initial symmetry breaking event is thought to be induced by shallow gradients of diffusible signals, such as TGF- $\beta$ and neurotrophins; contact with earlier formed cells may also play a role. These small environmental signals are then amplified by positive feedback loops and interpreted by several intracellular signaling cascades that ultimately impinge on the cytoskeleton, leading to spatial differences in actin-based motility, microtubule stability, and microtubulebased transport that underlie the distinct patterns of growth of axons and dendrites. Manipulating these signaling pathways can cause neurons to make multiple axons or can prevent axon formation. Mathematical models have been put forward to account for the initial symmetry breaking events and for the inhibitory processes that prevent formation of multiple axons (Inagaki et al., 2011; Takano et al., 2017). We are now poised to integrate work in culture with studies in multiple model organisms and to broaden our understanding of the development of polarity to include multiple types of neurons (Yogev and Shen, 2017).

\section{Chance and design}

Anyone reading scientific biography, or reflecting on his own history, cannot help but be struck by the role of chance in scientific discovery: as Darwin tells the story, the shape of his nose almost kept him from serving on the H.M.S. Beagle, which proved to be the defining event in his career. The work that led to the paper that is the subject of this article was often marked by serendipitous results; advice from colleagues, who could offer a different perspective, also played a key role. The path was so slow and circuitous that I often wonder how things would have turned out if I had faced the pressures young investigators face today. But chance played an even larger role than I have admitted so far. The defining event in my career was my decision to work as a postdoc with Max Cowan and the way our interests intersected. As a graduate student, I gave a great deal of thought to the work I planned to do as a postdoc, even writing a National Institutes of Health fellowship to support that work. I had no idea that Richard Nixon would impound National Institutes of Health training funds, forcing me to find another laboratory at the last minute. That led me to contact Max, and it was my good fortune that he was willing to take me on with little notice (and had the funds to do so). Perhaps Nixon should have been mentioned in the acknowledgments of our paper.

\section{The authors, three decades on}

Carlos Dotti is a professor at the Spanish National Research Council in Madrid. His current interests include aging and associated changes in synaptic efficacy. Chris Sullivan completed his M.D. at Albany Medical College, then went on to residency and fellowship training in obstetrics and gynecology. He is currently a physician in Tucson, Arizona, where he specializes in high-risk pregnancy management. Gary Banker is presently a Senior Scientist at the Jungers Center in Portland Oregon, with retirement very much on his mind.

\section{References}

Al-Ali H, Beckerman SR, Bixby JL, Lemmon VP (2017) In vitro models of axon regeneration. Exp Neurol 287:423-434. CrossRef Medline

Armijo-Weingart L, Gallo G (2017) It takes a village to raise a branch: cellular mechanisms of the initiation of axon collateral branches. Mol Cell Neurosci 84:36-47. CrossRef Medline

Ashrafi G, Schlehe JS, LaVoie MJ, Schwarz TL (2014) Mitophagy of damaged mitochondria occurs locally in distal neuronal axons and requires PINK1 and parkin. J Cell Biol 206:655-670. CrossRef Medline

Baas PW, Deitch JS, Black MM, Banker GA (1988) Polarity orientation of microtubules in hippocampal neurons: uniformity in the axon and nonuniformity in the dendrite. Proc Natl Acad Sci U S A 85:8335-8339. CrossRef Medline

Banker GA (1980) Trophic interactions between astroglial cells and hippocampal neurons in culture. Science 209:809-810. CrossRef Medline

Banker GA, Cowan WM (1977) Rat hippocampal neurons in dispersed cell culture. Brain Res 126:397-442. CrossRef Medline

Banker GA, Cowan WM (1979) Further observations on hippocampal neurons in dispersed cell culture. J Comp Neurol 187:469-493. CrossRef Medline

Bartlett WP, Banker GA (1984a) An electron microscopic study of the development of axons and dendrites by hippocampal neurons in culture: I. Cells which develop without intercellular contacts. J Neurosci 4:19441953. Medline

Bartlett WP, Banker GA (1984b) An electron microscopic study of the development of axons and dendrites by hippocampal neurons in culture: II. Synaptic relationships. J Neurosci 4:1954-1965. Medline

Bentley M, Banker G (2016) The cellular mechanisms that maintain neuronal polarity. Nat Rev Neurosci 17:611-622. CrossRef Medline

Bottenstein JE, Sato GH (1979) Growth of a rat neuroblastoma cell line in serum-free supplemented medium. Proc Natl Acad Sci U S A 76:514517. CrossRef Medline

Bray D (1970) Surface movements during the growth of single explanted neurons. Proc Natl Acad Sci U S A 65:905-910. CrossRef Medline

Bray D (1973) Branching patterns of individual sympathetic neurons in culture. J Cell Biol 56:702-712. CrossRef Medline

Bunge MB (2004) Autobiography. In: The history of neuroscience in autobiography (Squire, LR, ed), Vol 4, pp 40-72. San Diego, CA: Elsevier Academic.

Bunge RP, Rees R, Wood P, Burton H, Ko CP (1974) Anatomical and physiological observations on synapses formed on isolated autonomic neurons in tissue culture. Brain Res 66:401-412. CrossRef

Cáceres A, Banker GA, Binder L (1986) Immunocytochemical localization of tubulin and microtubule-associated protein 2 during the development of hippocampal neurons in culture. J Neurosci 6:714-722. Medline

Cid-Arregui A, De Hoop M, Dotti CG (1995) Mechanisms of neuronal polarity. Neurobiol Aging 16:239-243. CrossRef Medline

Cotman CW, Banker G (1974) The making of a synapse. In: Reviews of neuroscience (Ehrenpreis S, Kopin I), Vol 1, pp 1-62. New York: Raven.

Cowan WM (2004) Autobiography In: The history of neuroscience in autobiography (Squire, LR, ed), Vol 4, pp 144-208. San Diego, CA: Elsevier Academic.

Craig AM, Blackstone CD, Huganir RL, Banker G (1994) Selective clustering of glutamate and gamma-aminobutyric acid receptors opposite terminals releasing the corresponding neurotransmitters. Proc Natl Acad Sci U S A 91:12373-12377. CrossRef Medline

Craig AM, Banker G, Chang W, McGrath ME, Serpinskaya AS (1996) Clustering of gephyrin at GABAergic but not glutamatergic synapses in cultured rat hippocampal neurons. J Neurosci 16:3166-3177. Medline

Dotti CG, Banker GA (1987) Experimentally induced alteration in the polarity of developing neurons. Nature 330:254-256. CrossRef Medline

Dotti CG, Simons K (1990) Polarized sorting of viral glycoproteins to the axon and dendrites of hippocampal neurons in culture. Cell 62:63-72. CrossRef Medline

Dotti CG, Sullivan CA, Banker GA (1988) The establishment of polarity by hippocampal neurons in culture. J Neurosci 8:1454-1468. Medline 
Esch T, Lemmon V, Banker G (1999) Local presentation of substrate molecules directs axon specification by cultured hippocampal neurons. J Neurosci 19:6417-6426. Medline

Esch T, Lemmon V, Banker G (2000) Differential effects of NgCAM and $\mathrm{N}$-cadherin on the development of axons and dendrites by cultured hippocampal neurons. J Neurocytol 29:215-223. CrossRef Medline

Fang C, Imberdis T, Garza MC, Wille H, Harris DA (2016) A neuronal culture system to detect prion synaptotoxicity. PLoS Pathog 12:e1005623. CrossRef Medline

Feng S, Arnold DB (2016) Techniques for studying protein trafficking and molecular motors in neurons. Cytoskeleton 73:508-515. CrossRef Medline

Fischbach GD (1972) Synapse formation between dissociated nerve and muscle cells in low density cell cultures. Dev Biol 28:407-429. CrossRef Medline

Fletcher TL, Cameron P, De Camilli P, Banker G (1991) The distribution of synapsin I and synaptophysin in hippocampal neurons developing in culture. J Neurosci 11:1617-1626. Medline

Fletcher TL, De Camilli P, Banker G (1994) Synaptogenesis in hippocampal cultures: evidence indicating that axons and dendrites become competent to form synapses at different stages of neuronal development. J Neurosci 14:6695-6706. Medline

Flynn KC, Pak CW, Shaw AE, Bradke F, Bamburg JR (2009) Growth conelike waves transport actin and promote axonogenesis and neurite branching. Dev Neurobiol 69:761-779. CrossRef Medline

Goslin K, Banker G (1989) Experimental observations on the development of polarity by hippocampal neurons in culture. J Cell Biol 108:1507-1516. CrossRef Medline

Harrison RG (1914) The reaction of embryonic cells to solid structures. J Exp Zool 17:521-544. CrossRef

Inagaki N, Toriyama M, Sakumura Y (2011) Systems biology of symmetry breaking during neuronal polarity formation. Dev Neurobiol 71:584593. CrossRef Medline

Kaech S, Banker G (2006) Culturing hippocampal neurons. Nat Protoc 1:2406-2415. CrossRef Medline

Kleiman R, Banker G, Steward O (1990) Differential subcellular localization of particular mRNAs in hippocampal neurons in culture. Neuron 5:821830. CrossRef Medline

Lamoureux P, Ruthel G, Buxbaum RE, Heidemann SR (2002) Mechanical tension can specify axonal fate in hippocampal neurons. J Cell Biol 159: 499-508. CrossRef Medline

Letourneau PC (1975) Possible roles for cell-to-substratum adhesion in neuronal morphogenesis. Dev Biol 44:77-91. CrossRef Medline

Lewis TL Jr, Courchet J, Polleux F (2013) Cell biology in neuroscience: cellular and molecular mechanisms underlying axon formation, growth, and branching. J Cell Biol 202:837-848. CrossRef Medline

Luo L, O'Leary DD (2005) Axon retraction and degeneration in development and disease. Annu Rev Neurosci 28:127-156. CrossRef Medline
Namba T, Funahashi Y, Nakamuta S, Xu C, Takano T, Kaibuchi K (2015) Extracellular and intracellular signaling for neuronal polarity. Physiol Rev 95:995-1024. CrossRef Medline

Nirschl JJ, Ghiretti AE, Holzbaur EL (2017) The impact of cytoskeletal organization on the local regulation of neuronal transport. Nat Rev Neurosci 18:585-597. CrossRef Medline

Noctor SC, Martínez-Cerdeño V, Ivic L, Kriegstein AR (2004) Cortical neurons arise in symmetric and asymmetric division zones and migrate through specific phases. Nat Neurosci 7:136-144. CrossRef Medline

Ruthel G, Banker G (1999) Role of moving growth cone-like "wave" structures in the outgrowth of cultured hippocampal axons and dendrites. J Neurobiol 39:97-106. CrossRef Medline

Schelski M, Bradke F (2017) Neuronal polarization: from spatiotemporal signaling to cytoskeletal dynamics. Mol Cell Neurosci 84:11-28. CrossRef Medline

Shepherd GM (1991) Foundations of the neuron doctrine. New York, NY: Oxford UP.

Siddiqui TJ, Craig AM (2011) Synaptic organizing complexes. Curr Opin Neurobiol 21:132-143. CrossRef Medline

Soo Hoo LS, Banna CD, Radeke CM, Sharma N, Albertolle ME, Low SH, Weimbs T, Vandenberg CA (2016) The SNARE protein Syntaxin 3 confers specificity for polarized axonal trafficking in neurons. PLoS One 11: e0163671. CrossRef Medline

Steward O, Banker GA (1992) Getting the message from the gene to the synapse: sorting and intracellular transport of RNA in neurons. Trends Neurosci 15:180-186. CrossRef Medline

Tabata H, Nakajima K (2003) Multipolar migration: the third mode of radial neuronal migration in the developing cerebral cortex. J Neurosci 23:9996-10001. Medline

Takano T, Wu M, Nakamuta S, Naoki H, Ishizawa N, Namba T, Watanabe T, Xu C, Hamaguchi T, Yura Y, Amano M, Hahn KM, Kaibuchi K (2017) Discovery of long-range inhibitory signaling to ensure single axon formation. Nat Commun 8:33. CrossRef Medline

Winans AM, Collins SR, Meyer T (2016) Waves of actin and microtubule polymerization drive microtubule-based transport and neurite growth before single axon formation. Elife 5:e12387. CrossRef Medline

Withers GS, Higgins D, Charette M, Banker G (2000) Bone morphogenetic protein-7 enhances dendritic growth and receptivity to innervation in cultured hippocampal neurons. Eur J Neurosci 12:106-116. CrossRef Medline

Yamamoto H, Demura T, Morita M, Banker GA, Tanii T, Nakamura S (2012) Differential neurite outgrowth is required for axon specification by cultured hippocampal neurons. J Neurochem 123:904-910. CrossRef Medline

Yogev S, Shen K (2017) Establishing neuronal polarity with environmental and intrinsic mechanisms. Neuron 96:638-650. CrossRef Medline 